\title{
Factors Influencing the One- and Two-Year Growth Response in Children Treated with Growth Hormone: Analysis from an Observational Study
}

\author{
Judith Ross, ${ }^{1}$ Peter A. Lee, ${ }^{2}$ Robert Gut, ${ }^{3}$ and John Germak ${ }^{3}$ \\ ${ }^{1}$ Department of Pediatrics, Thomas Jefferson University, 1025 Walnut Street, Philadelphia, PA 19107, USA \\ ${ }^{2}$ Department of Pediatrics, The Milton S. Hershey Medical Center, Penn State College of Medicine, 500 University Drive, \\ Suite 1100, Hershey, PA 17033, USA \\ ${ }^{3}$ Novo Nordisk Inc, 100 College Road West, Princeton, NJ 08540, USA
}

Correspondence should be addressed to Judith Ross, judith.ross@jefferson.edu

Received 11 August 2010; Accepted 21 September 2010

Academic Editor: Pinchas S. Cohen

Copyright ( $) 2010$ Judith Ross et al. This is an open access article distributed under the Creative Commons Attribution License, which permits unrestricted use, distribution, and reproduction in any medium, provided the original work is properly cited.

\begin{abstract}
To assess gender-, pubertal-, age-related differences in change from baseline height standard deviation score ( $\triangle$ HSDS), data from 5,797 growth hormone $(\mathrm{GH})$ naïve pediatric patients (<18 years) with growth hormone deficiency (GHD), multiple pituitary hormone deficiency (MPHD), Turner syndrome (TS), small for gestational age (SGA), Noonan syndrome (NS), and idiopathic short stature (ISS) were obtained from the ANSWER (American Norditropin Studies: Web-enabled Research) Program registry. For patients with SGA, $\triangle$ HSDS at year 1 was significantly greater for males versus females $(P=.016)$, but no other gender differences were observed. For patients with GHD, $\triangle$ HSDS was greater in prepubertal than in pubertal patients. Younger patients for both genders ( $<11$ years for boys; $<10$ years for girls) showed a greater $\Delta$ HSDS $(P<.05$ for GHD, MPHD, and ISS). Overall, positive $\triangle$ HSDSs were observed in all patients, with greater growth responses in younger prepubertal children, emphasizing the importance of starting GH treatment early.
\end{abstract}

\section{Introduction}

Growth hormone $(\mathrm{GH})$ promotes linear growth that is mediated, at least in part, through increased production of insulin-like growth factor-1 (IGF-I) [1]. The pediatric indications for recombinant human GH approved by the United States Food and Drug Administration (FDA) include treatment of children with growth failure due to GH deficiency; children with short stature associated with Noonan syndrome (NS), Turner syndrome (TS), and Prader-Willi syndrome (PWS); children with short stature born small for gestational age (SGA) who have not reached normal growth range by age $2-4$ years; short stature with homeoboxcontaining gene deficiency; children with chronic renal insufficiency; children with idiopathic short stature (ISS) who are $>2.25$ standard deviations (SD) below the mean in height and who are unlikely to catch up in height [14].
Treatment with GH has been shown to be highly effective for the treatment of pediatric patients with GH deficiency, with increases in both short-term growth and adult height [5-8]. Yet, the treatment outcomes are variable. Review of results in which GH was administered to GH-deficient children $<4$ years of age indicated that, on average, they achieved adult heights about $1 \mathrm{SD}$ below the population mean [5]. Another report demonstrated that GH administration to children with GH deficiency (GHD) results in nearly normal adult height and normal peak bone mass, as well as potentially decreasing the risk of cardiovascular disease [6]. Meta-analysis of results from 10 randomized clinical trials in which GH was administered to children with ISS indicated that short-term height gains can range from zero to approximately 0.7 SDS over 1 year, and that this treatment also improved near-adult height. However, despite these increases, patients attained heights that were relatively short when compared with peers of normal stature [7]. 
A meta-analysis of 4 studies that included 365 girls with TS indicated that administration of GH significantly increased growth velocity over 1 and 2 years. Results from one trial that reported adult height in TS, indicated a mean height of $148 \mathrm{~cm}$ in $61 \mathrm{GH}$-treated patients versus $141 \mathrm{~cm}$ in 43 who were untreated [8].

Results from a number of studies have indicated that specific patient factors, such as age and gender, may significantly influence the response to GH therapy. Assessment of responses to $\mathrm{GH}$ treatment in 111 short-stature, prepubertal, $\mathrm{GH}$-deficient children indicated that the dose response to $0.025,0.05$, or $0.1 \mathrm{mg} / \mathrm{kg} /$ day, for both auxological and biochemical parameters, differed between prepubertal females and males. Males had a linear GH dose response, whereas females had an apparent plateau of both linear growth and IGF-I standard deviation score (SDS) responses at $0.05 \mathrm{mg} / \mathrm{kg}$ per day [9]. Results from some registry and modeling studies have suggested that gender may play a role in the level of growth response to GH treatment $[10,11]$.

Norditropin [somatropin (rDNA origin) injection] is indicated for the treatment of children with growth failure due to GHD, with short stature associated with NS and TS, and with short stature in children born SGA with no catchup growth by age $2-4$ years. It is also indicated for treatment of adults with either adult or childhood onset of GHD [12]. Since 2002, the ANSWER (American Norditropin Studies: Web-enabled Research) Program has collected information on patients receiving Norditropin. The use of Norditropin in patients within the ANSWER Program is at the discretion of the participating physicians and may include additional diagnostic conditions that warrant treatment with GH. The present study was carried out using data from the ANSWER Program registry to assess gender-, pubertal-, and age-related differences in change from baseline in height standard deviation scores (HSDSs) across different diagnostic categories of GH-treatment-naïve pediatric patients who were treated with Norditropin.

\section{Subjects and Methods}

2.1. ANSWER Program Registry. Data for this analysis were obtained from the ANSWER Program registry, a collection of long-term efficacy and safety information on patients treated with Norditropin in the United States. The ANSWER Program registry enrolls GH-treatment-naïve and -nonnaïve patients. Patient histories and physical examination data are entered by participating physician investigators using the ANSWER Program registry reporting form, a webbased data entry tool. For the purpose of this analysis, patients from the following categories were included: (1) GHD (isolated/idiopathic), (2) multiple pituitary hormone deficiency (MPHD), (3) TS, (4) SGA, (5) NS, and (6) ISS. Only results from GH-treatment-naïve patients were included in the analyses.

2.2. Data Collection for ANSWER Program Registry. At the initial visit, study investigators collected baseline HSDS, weight, pretreatment bone age, Tanner stage (according to breast and pubic hair), maximal stimulated serum GH concentration, and serum IGF-I concentrations. Data collected from follow-up clinic visits included GH dose/frequency, height, weight, Tanner stage, and IGF-I concentration.

2.3. Evaluation Methods for Analysis. Data from pediatric patients who were treatment naïve were collected and analyzed at baseline, 1 year, and 2 years. Data at each time point were collected within a 3-month window. HSDS ( $\mathrm{z}$ score) was calculated according to the standard formulas provided by the Center for Disease Control and Prevention [13]. The following rules were used to exclude patients from analysis: baseline age $<0$ or $>18$ years, baseline HSDS less than -5 or greater than +2 , and baseline height $<35$ or $>200 \mathrm{~cm}$. Potential subjects were excluded from the analysis if key variables had baseline or subsequent values that were deemed physically or chronologically impossible $(3.77 \%$ of potential subjects were excluded according to these criteria).

Data analyzed included HSDS change from baseline ( $\triangle$ HSDS) at 1 year and 2 years of GH treatment, $\Delta$ HSDS by gender and pubertal status (defined by Tanner stage classification [14]) or age at start of treatment, and a least-squares means analysis of $\triangle H S D S$ by gender. Pubertal status was assigned by the physician and categorized as follows: prepubertal patients (Tanner stage I throughout), prepubertal/pubertal patients (transitioned from Tanner stage I to Tanner stage II or more), and pubertal patients (Tanner stage II or more at baseline). For analyses of age at start of treatment, age ranges were defined to be $<11$ or $\geq 11$ years of age for male patients, and $<10$ or $\geq 10$ years of age for female patients.

Statistical comparisons of $\Delta$ HSDS between age groups stratified by gender and different diagnostic categories were conducted using the two-sample $t$-test. No adjustment for multiplicity of testing was done. The differences were considered statistically significant if the corresponding $P$ values $\leq .05$.

\section{Results}

The ANSWER Program registry (as of November 2009) contained information for 5,797 GH-treatment-naïve patients from the following categories: GHD (isolated/idiopathic), MPHD, TS, SGA, NS, and ISS.

3.1. Patient Demographics. Baseline demographic characteristics for the subjects are summarized in Table 1. The study included 3,870 patients with GHD, 355 with MPHD, 382 with TS, 360 with SGA, 79 with NS, and 751 with ISS. Information summarized in Table 1 indicates that the subjects with MPHD, SGA, and TS were generally younger at baseline compared with those in the other diagnostic categories. The lowest mean peak GH levels were observed in patients with GHD (isolated/idiopathic) and MPHD, 5.3 and $3.1 \mathrm{ng} / \mathrm{mL}$, respectively. On average, older baseline age was observed for patients with GHD, NS, and ISS. Baseline $\mathrm{GH}$ dose (in $\mathrm{mg} / \mathrm{kg}$ ) information for the different diagnostic categories demonstrates slightly higher doses for ISS, TS, 
TABLe 1: Baseline demographics.

\begin{tabular}{|c|c|c|c|c|c|c|c|c|c|c|c|c|}
\hline & & GHD & & MPHD & & TS & & SGA & & NS & & ISS \\
\hline & $N$ & Mean (SD) & $N$ & Mean (SD) & $N$ & Mean (SD) & $N$ & Mean (SD) & $N$ & Mean (SD) & $N$ & Mean (SD) \\
\hline Gender, M/F & & $2,918 / 952$ & & $220 / 135$ & & $0 / 382$ & & $224 / 136$ & & $58 / 21$ & & $528 / 223$ \\
\hline Age, yr & 3,870 & $10.8 \pm 3.54$ & 355 & $7.5 \pm 5.45$ & 382 & $8.6 \pm 4.03$ & 360 & $8.4 \pm 3.74$ & 79 & $9.6 \pm 3.76$ & 751 & $11.2 \pm 3.06$ \\
\hline HSDS & 3,870 & $-2.2 \pm 0.89$ & 355 & $-1.9 \pm 1.39$ & 382 & $-2.6 \pm 0.9$ & 360 & $-2.6 \pm 0.89$ & 79 & $-2.7 \pm 0.70$ & 751 & $-2.3 \pm 0.75$ \\
\hline IGF-I SDS & 3,360 & $-2.5 \pm 1.42$ & 184 & $-3.2 \pm 1.67$ & 220 & $-1.9 \pm 1.22$ & 258 & $-2.4 \pm 1.68$ & 65 & $-2.8 \pm 1.27$ & 701 & $-2.2 \pm 1.45$ \\
\hline Bone age, yrs & 3,369 & $9.3 \pm 3.41$ & 186 & $8.5 \pm 4.5$ & 256 & $8.0 \pm 3.46$ & 296 & $7.3 \pm 3.68$ & 66 & $8.0 \pm 3.75$ & 667 & $9.6 \pm 3.31$ \\
\hline $\begin{array}{l}\text { Baseline GH } \\
\text { dose, } \mathrm{mg} / \mathrm{kg} / \text { day }\end{array}$ & 3,514 & $0.047(0.0121)$ & 319 & $0.039(0.0123)$ & 357 & $0.051(0.0098)$ & 325 & $0.052(0.0137)$ & 72 & $0.047(0.0106)$ & 644 & $0.050(0.0127)$ \\
\hline $\begin{array}{l}\text { Peak GH, } \\
\mathrm{ng} / \mathrm{mL}\end{array}$ & 3,326 & $5.3 \pm 2.77$ & 202 & $3.1 \pm 3.04$ & 16 & $18.2 \pm 31.54$ & 138 & $14.4 \pm 13.69$ & 32 & $10.8 \pm 9.13$ & 542 & $17.1 \pm 20.09$ \\
\hline $\begin{array}{l}\text { Baseline HSDS } \\
\text { (males) }\end{array}$ & 2918 & $-2.1 \pm 0.85$ & 220 & $-1.9 \pm 1.36$ & - & - & 224 & $-2.5 \pm 0.83$ & 58 & $-2.6 \pm 0.69$ & 528 & $-2.2 \pm 0.71$ \\
\hline $\begin{array}{l}\text { Baseline HSDS } \\
\text { (female) }\end{array}$ & 952 & $-2.4 \pm 0.97$ & 135 & $-1.9 \pm 1.44$ & 382 & $-2.6 \pm 0.90$ & 136 & $-2.7 \pm 0.97$ & 21 & $-2.9 \pm 0.69$ & 223 & $-2.4 \pm 0.82$ \\
\hline
\end{tabular}

GHD: idiopathic growth hormone deficiency; MPHD: multiple pituitary hormone deficiency; TS: Turner syndrome; SGA: short for gestational age; NS: Noonan syndrome; ISS: idiopathic short stature.

SGA, and GHD compared to MPHD patients, which may be as expected, since they are the most GH deficient.

Although the dose for patients with NS may be slightly lower than expected, this may be due to the fact that there are fewer patients in this category. Baseline HSDS for male and female subjects in each diagnostic group are also summarized in Table 1. Overall, mean HSDS values for different diagnostic groups varied from -1.9 to -2.6 for males and -1.9 to -2.9 for females. Generally, greater baseline HSDS were observed with male patients and significant differences were observed between male and female baseline HSDS for patients with GHD, ISS, and NS $(P<.0001, P=.0121$, $P=.0459$, resp.).

3.2. Effects of GH Treatment on HSDS. Effects of GH treatment on HSDS are summarized in Figures 1 and 2, respectively, for each diagnosis category and for male and female subjects in each of these groups. The overall effects of GH treatment on absolute values for HSDS across diagnostic categories are shown in Figure 1(a). Patients in all treatment groups had positive changes in HSDS over 2 years of followup. $\triangle$ HSDS at 1 year ranged from 0.4 for ISS, TS, and NS to 0.7 for MPHD. At the end of 2 years, the $\triangle$ HSDS ranged from 0.6 for NS to 1.0 for GHD, MPHD, and SGA. Corresponding average GH doses at baseline and end of year 1 and year 2 are depicted in Figure 1(b). For all diagnostic categories, dose generally remained stable over two years except for NS at end of year 1 where a mild increase in dose is apparent. Not surprisingly, subjects with MPHD received the lowest GH dose over two years, consistent with the greater degree of GHD as reflected in their very low serum IGFI and peak GH concentrations at baseline (Table 1). The results in Figure 2 show that treatment resulted in substantial changes in HSDS in both the male and female subjects over 2 years of treatment. Analysis of results for all diagnostic categories except SGA indicated no significant differences between results for male and female subjects over 2 years of treatment. For subjects with SGA, the $\Delta$ HSDS in the first year of treatment was significantly greater for male versus female subjects ( 0.69 versus $0.53, P=.016)$.

$\triangle$ HSDS for prepubertal and pubertal patients with GHD was analyzed according to whether they remained prepubertal, became pubertal, or were pubertal during the entire 2-year treatment interval (Table 2). $\triangle$ HSDS (mean \pm SD) in both years of treatment was observed for subjects who were prepubertal $(0.64 \pm 0.53$ year $1 ; 1.15 \pm 0.73$ year $2)$, pubertal $(0.48 \pm 0.36$ year $1 ; 0.95 \pm 0.56$ year 2$)$, or who transitioned from prepubertal to pubertal during the 2-year study period $(0.50 \pm 0.41$ year $1 ; 0.94 \pm 0.53$ year 2$)$.

Table 3 shows $\triangle$ HSDS for male and female subjects who were stratified by age at treatment start $(<11$ or $\geq 11$ for males, $<10$ or $\geq 10$ for females). Younger male and female subjects from each diagnostic group generally showed greater $\Delta$ HSDS. Except for Noonan syndrome and SGA, results for male and female subjects in each diagnostic category indicated significantly greater $\triangle$ HSDS at both years 1 and 2 for those with initiation of treatment at the younger age. Except for male patients in year 1, there was no statistically significant difference observed between younger and older Noonan syndrome patients. A similar lack of difference between age groups was noted for female SGA subjects.

\section{Discussion}

Results from 2 years of GH treatment of subjects in the ANSWER Program registry demonstrated increased HSDS from baseline in a large cohort of male and female subjects with ISS, GHD, MPHD, SGA, TS, and NS. Study results did not demonstrate any substantial gender differences for patients with ISS, GHD, MPHD, NS, or SGA. The only difference between male and female subjects that achieved statistical significance was $\triangle$ HSDS at 1 year in those with 


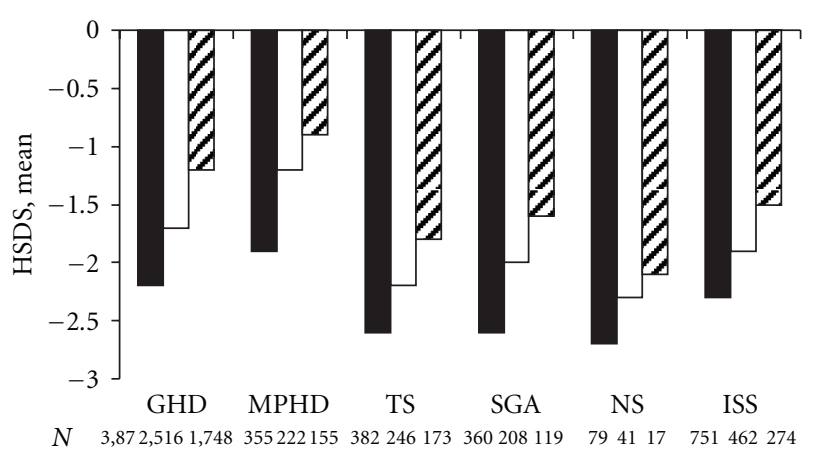

$\square$ Baseline
$\square$ Year 1
$\square$ Year 2

(a)

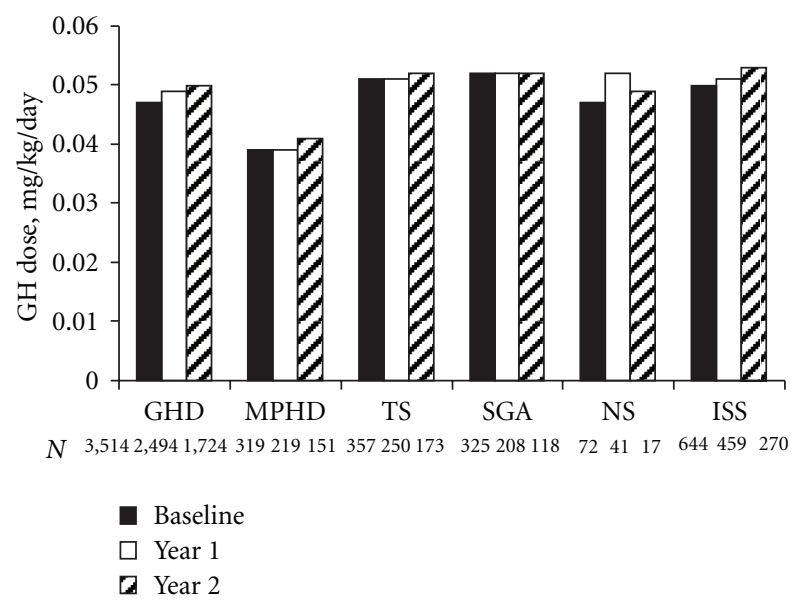

(b)

Figure 1: (a) HSDS at baseline, year 1, and year 2 following treatment with GH for patients with GHD, MPHD, TS, SGA, NS, or ISS. (b) GH dose at baseline, year 1, and year 2 for patients with GHD, MPHD, TS, SGA, NS, or ISS. GHD: isolated/idiopathic growth hormone deficiency; MPHD: multiple pituitary hormone deficiency; TS: Turner syndrome; SGA: short for gestational age; NS: Noonan syndrome; ISS: idiopathic short stature.

SGA (male > female), which may or may not be clinically significant.

The general lack of effect of gender on response to GH treatment observed in this registry analysis is consistent with results from a large number of studies that evaluated effects of gender on response to GH. Analysis of results from the Pfizer Kabi International Growth Study (KIGS) database indicated no significant gender-related differences in effects of $\mathrm{GH}$ on growth velocity or HSDS over 2 or 3 years of treatment [15]. Analysis of the short- and long-term effects of GH treatment on growth in prepubertal children with chronic renal failure also indicated no significant effects of gender [16]. Evaluation of predictors of response to treatment with GH for up to 7 years in 8,018 patients with ISS indicated no significant effect of gender on first-year growth velocity or change from baseline in HSDS [17]. In contrast,

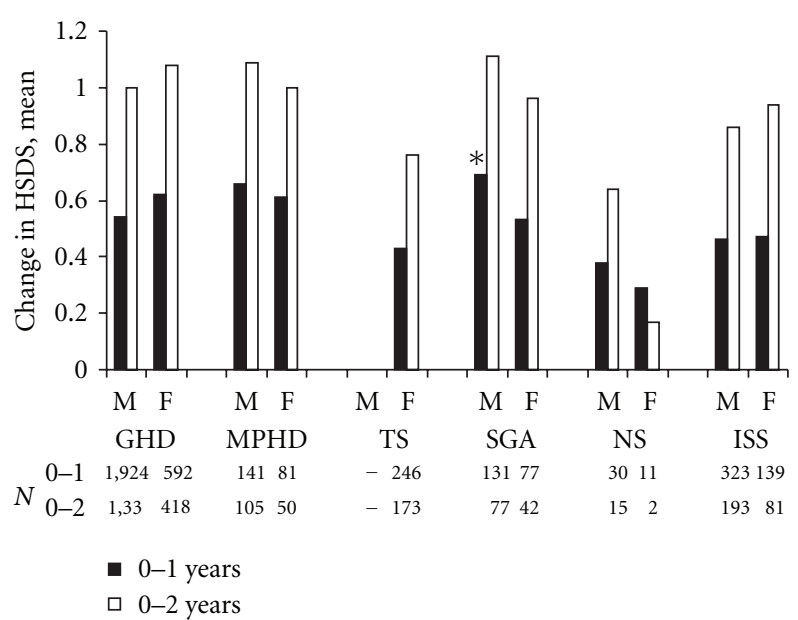

Figure 2: HSDS change from baseline by gender following treatment with GH for patients with GHD, MPHD, TS, SGA, NS, and ISS measured over 2 years. ${ }^{*}$ male $>$ female, $P=.016$. GHD: isolated/idiopathic growth hormone deficiency; MPHD: multiple pituitary hormone deficiency; TS: Turner syndrome; SGA: short for gestational age; NS: Noonan syndrome; ISS: idiopathic short stature.

TABLE 2: HSDS change from baseline by pubertal status for patients with GHD.

\begin{tabular}{lclcl}
\hline & \multicolumn{2}{c}{ Year 1 } & \multicolumn{2}{l}{ Year 2 } \\
& $N$ & Mean \pm SD & $N$ & Mean \pm SD \\
\hline Prepubertal $^{\text {a }}$ & 1128 & $0.64 \pm 0.53$ & 610 & $1.15 \pm 0.73$ \\
Prepubertal/Pubertal & 572 & $0.50 \pm 0.41$ & 638 & $0.94 \pm 0.53$ \\
Pubertal & 772 & $0.48 \pm 0.36$ & 474 & $0.95 \pm 0.56$ \\
\hline
\end{tabular}

a Pubertal status assigned by the physician; prepubertal were Tanner I throughout, prepubertal/pubertal patients transitioned into Tanner II or more, pubertal patients were Tanner II or more at baseline.

results from a French registry that included 2,852 patients with idiopathic GHD indicated that female gender was a significant positive predictor of adult height gain with $\mathrm{GH}$ treatment [10].

Analyses did show that $\triangle$ HSDS was significantly greater for subjects who started GH treatment at a younger age. While results from the ANSWER Program registry suggest that many patients start GH treatment later than desired, multiple studies suggest better growth outcomes with earlier intervention. For example, the Consensus Statement on the Diagnosis and Treatment of Children with Idiopathic Short Stature indicates that the optimal age for initiation of treatment is 5 years of age to early puberty [18]. The mean age at initiation of therapy for children with ISS in this analysis was 11.2 years and near the upper end of the recommended age range. Similarly, the International Small for Gestational Age Advisory Board Consensus Development Conference Statement indicated that patients who begin therapy at 9-10 years of age will experience lower growth velocity than those who start treatment earlier [19]. 
TABLE 3: HSDS change from baseline stratified by age at treatment start and gender.

\begin{tabular}{|c|c|c|c|c|c|c|c|c|c|c|c|}
\hline & & \multicolumn{5}{|c|}{ Male } & \multicolumn{5}{|c|}{ Female } \\
\hline & & \multicolumn{2}{|c|}{$<11$ years } & \multicolumn{2}{|c|}{$\geq 11$ years } & \multirow[t]{2}{*}{$P$-value } & \multicolumn{2}{|c|}{$<10$ years } & \multicolumn{2}{|c|}{$\geq 10$ years } & \multirow[t]{2}{*}{$P$-value } \\
\hline & & $N$ & Mean \pm SD & $N$ & Mean \pm SD & & $N$ & Mean \pm SD & $N$ & Mean \pm SD & \\
\hline \multirow{2}{*}{ GHD } & Year 1 & 759 & $0.75 \pm 0.52$ & 1,169 & $0.41 \pm 0.36$ & $<.0001$ & 272 & $0.78 \pm 0.54$ & 324 & $0.48 \pm 0.40$ & $<.0001$ \\
\hline & Year 2 & 555 & $1.20 \pm 0.68$ & 780 & $0.85 \pm 0.54$ & $<.0001$ & 206 & $1.25 \pm 0.65$ & 214 & $0.91 \pm 0.58$ & $<.0001$ \\
\hline \multirow{2}{*}{ MPHD } & Year 1 & 96 & $0.85 \pm 1.07$ & 45 & $0.27 \pm 0.40$ & $<.0001$ & 46 & $0.86 \pm 0.82$ & 35 & $0.29 \pm 0.45$ & .0002 \\
\hline & Year 2 & 81 & $1.26 \pm 1.07$ & 24 & $0.54 \pm 0.82$ & .0033 & 27 & $1.33 \pm 1.22$ & 23 & $0.60 \pm 0.70$ & .0114 \\
\hline \multirow{2}{*}{ TS } & Year 1 & - & - & - & - & - & 145 & $0.56 \pm 0.40$ & 101 & $0.25 \pm 0.36$ & $<.0001$ \\
\hline & Year 2 & - & - & - & - & - & 107 & $0.84 \pm 0.54$ & 66 & $0.63 \pm 0.56$ & .0168 \\
\hline \multirow{2}{*}{ SGA } & Year 1 & 101 & $0.82 \pm 0.53$ & 30 & $0.27 \pm 0.28$ & $<.0001$ & 52 & $0.58 \pm 0.55$ & 25 & $0.41 \pm 0.35$ & .0931 \\
\hline & Year 2 & 63 & $1.23 \pm 0.60$ & 14 & $0.59 \pm 0.51$ & .0005 & 29 & $1.00 \pm 0.74$ & 13 & $0.87 \pm 0.51$ & .5670 \\
\hline \multirow{2}{*}{ NS } & Year 1 & 18 & $0.53 \pm 0.41$ & 12 & $0.16 \pm 0.38$ & .0212 & 6 & $0.31 \pm 0.45$ & 5 & $0.26 \pm 0.47$ & .8565 \\
\hline & Year 2 & 10 & $0.83 \pm 0.84$ & 5 & $0.25 \pm 0.45$ & .1763 & 1 & $0.23 \pm-$ & 1 & $0.10 \pm-$ & - \\
\hline \multirow{2}{*}{ ISS } & Year 1 & 115 & $0.60 \pm 0.44$ & 208 & $0.38 \pm 0.29$ & $<.0001$ & 47 & $0.71 \pm 0.37$ & 92 & $0.35 \pm 0.38$ & $<.0001$ \\
\hline & Year 2 & 83 & $0.96 \pm 0.63$ & 110 & $0.79 \pm 0.51$ & .0400 & 33 & $1.25 \pm 0.61$ & 48 & $0.73 \pm 0.62$ & .0004 \\
\hline
\end{tabular}

$P$ values are for comparisons between age groups for each year

GHD: isolated/idiopathic growth hormone deficiency; MPHD: multiple pituitary hormone deficiency; TS: Turner syndrome; SGA: short for gestational age; NS: Noonan syndrome; ISS: idiopathic short stature.

The mean age at initiation of treatment for subjects with SGA included in this analysis was 8.4 years. Guidelines for the treatment of childhood GHD do not provide specific guidance on the optimal time for initiation of therapy $[1,2]$. However, earlier recommendations from the Growth Hormone Research Society indicate that treatment should be initiated as soon as the diagnosis is made [20]. Current guidelines do not provide a specific recommendation for timing of treatment initiation in patients with TS $[1,21]$, but one review suggested treatment initiation at 4-6 years of age [22]. The Turner Syndrome Study Consensus Group suggested that treatment with GH should be considered as soon as growth failure is demonstrated and potential risks and benefits of treatment have been discussed with the family [21]. This recommendation is consistent with clinical trial results indicating that initiation of GH as early as 9 months of age in patients with TS is safe and results in significant improvements in length/height SDS [23]. Results from a study of 1,478 females with TS in Japan indicated that the percent of patients with initiation of treatment at $<5$ years old was $5.11 \%$ for the period of 1991 to 1994 but increased to $16.85 \%$ for the period from 2000 to 2004, with pretreatment mean HSDS scores of $-3.41 \pm 0.87$ and $-3.17 \pm 0.79$, respectively $(P<.0001)$. Mean ages at initiation of treatment for these 2 periods were 10.95 and 8.78 years, respectively [24].

Baseline data for subjects included in this analysis of the ANSWER Program registry also indicated lower mean baseline HSDS scores for female subjects compared with male subjects across all diagnostic categories, and these differences were significant for patients with GHD, ISS, and NS. This may be due to a referral bias with earlier recognition of short stature and treatment in male versus female patients. This bias in treatment has been documented in a recent analysis of results from 1,485 Australian children included in the OZGROW database [25]. Results from the United States also indicate that there is almost $2: 1$ male to female ratio for patients referred for GH treatment [26].

Overall, the $\triangle$ HSDS observed in this study for year 1 , ranging from $0.4-0.7$, and year 2 , ranging from $0.6-1.0$ across all diagnostic categories, is consistent with findings from other clinical trials of GH treatment. Results from a metaanalysis of 10 trials with 1-year follow-up data indicated a mean $\triangle$ HSDS of 0.43 for patients with ISS [27]. Within the meta-analysis study, 4 studies had 2-year follow-up data taken from a total of 128 patients, which indicated a $\triangle$ HSDS of about 0.7 [27]. In a registry study of 704 patients with TS, a 1-year gain in HSDS of 0.6 was observed [28]. Data from another registry of patients with isolated idiopathic GHD found a gain in HSDS of 1.0 following 3.6 years of treatment with GH but where the majority of the height was gained during the first 2 years [10].

The importance of timing of treatment initiation demonstrated by this analysis is also supported by results from other studies of pediatric patients treated with GH. A report by Ranke et. al. validating a mathematical model for predicting the response of pediatric patients with idiopathic GHD to treatment with GH reiterated that chronologic age at start of treatment and maximum baseline $\mathrm{GH}$ response were the top two (out of six) parameters predicting first year height velocity. Also, second and third year height velocity were primarily predicted by the growth velocity in the previous year [29]. Although the purpose of the current analysis was not to develop a prediction model, our results are consistent with both younger age at treatment start and baseline peak GH inversely correlating with first year growth response, particularly in GHD and MPHD subjects. In a recent followup analysis for predicting two-year growth responses to GH 
therapy in prepubertal children with either severe GHD, less severe GHD, TS, or SGA, Ranke and Lindberg developed criteria defining an adequate first year $\triangle$ HSDS [30]. For patients with severe GHD (peak $\mathrm{GH}<5 \mu \mathrm{g} / \mathrm{L}$ ), an adequate first year response was defined as $\triangle \mathrm{HSDS} \geq 0.4$, whereas for less severe GHD (peak GH 5-10 $\mu \mathrm{g} / \mathrm{L}$ ), TS, and SGA, a $\triangle$ HSDS $\geq 0.3$ in the first year indicated an adequate response. The growth responses to $\mathrm{GH}$ in the current analysis of subjects from the ANSWER Program registry would meet these criteria since the first year mean $\triangle$ HSDS ranged between 0.4 and 0.7 for all diagnostic categories. However, when stratified by age, this did not hold up for all older subjects (males $\geq 11$ and females $\geq 10$ ) in some categories (MPHD, TS, SGA, NS), emphasizing the importance of younger age at treatment start. In this regard, it is important to note that subjects included in our analysis ranged between 0.5 and 18 years of age, whereas the age range in the Ranke analysis model was 1 to 12 years [30].

According to a registry study that included information from 3,007 patients with idiopathic GH deficiency, 1378 with TS, and 65 with NS, the duration of prepubertal, GH treatment correlated significantly with achievement of nearnormal adult height [31]. Other registry studies have also suggested that prepubertal initiation of treatment results in greater improvements in HSDS. According to results from the National Registry of Growth Hormone Treatment in the Netherlands that included 342 patients with GHD, initiation of treatment before puberty resulted in a $\triangle$ HSDS of 0.71 versus 0.58 for those who started treatment after pubertal onset [32]. The French registry study of 2,852 patients with idiopathic GHD also demonstrated greater adult height gain with prepubertal initiation of GH treatment [10]. One exception to this general trend toward greater benefit of $\mathrm{GH}$ treatment in prepubertal versus pubertal patients involves results from a study of 83 patients with GHD who were treated for 2 to 7 years, that indicated no significant effect with respect to adult height achieved [33].

In conclusion, in this analysis of data from the ANSWER Program registry, GH treatment resulted in increased HSDS in subjects with idiopathic/isolated GHD, MPHD, TS, NS, and ISS. No consistent gender effect was observed in $\triangle$ HSDS after 2 years of therapy. However, on average, initiation of treatment at a younger age or before the start of puberty (GHD patients) resulted in greater $\triangle$ HSDS. Due to the greater growth response, which was apparent in younger, prepubertal children, the importance of starting growth hormone treatment at a younger age should continue to be emphasized.

\section{Disclosure}

Dr. J. Ross discloses that she is a consultant for Novo Nordisk, and she has received clinical study support from Novo Nordisk, Eli Lilly, and Pfizer. Dr. P. Lee is a consultant for Abbott and Novo Nordisk, and he has received clinical study support from Abbott, Novo Nordisk, Eli Lilly, Pfizer, and Ipsen. Drs. R. Gut and J. Germak are both employees of Novo Nordisk.

\section{Acknowledgments}

The authors would like to thank Jennifer R. Kent, $\mathrm{PhD}$, of DesignWrite, LLC, for providing writing and editorial assistance. Funding to support the preparation of this paper was provided by Novo Nordisk, Inc.

\section{References}

[1] H. Gharib, D. M. Cook, P. H. Saenger et al., "American Association of Clinical Endocrinologists medical guidelines for clinical practice for growth hormone use in adults and children-2003 update," Endocrine Practice, vol. 9, no. 1, pp. 64-76, 2003.

[2] T. A. Wilson, S. R. Rose, P. Cohen et al., "Update of guidelines for the use of growth hormone in children: the Lawson Wilkins Pediatric Endocrinology Society Drug and Therapeutics Committee," Journal of Pediatrics, vol. 143, no. 4, pp. 415-421, 2003.

[3] P. F. Collett-Solberg and A. Petryk, Changes in Recombinant Human Growth Hormone (rhGH) Prescribing Information, Lawson Wilkins Pediatric Endocrine Society, 2008, http:// www.lpes.org/policyStatements/changesrhGHprescribing_information_31408.pdf.

[4] P. E. Clayton, S. Cianfarani, P. Czernichow, G. Johannsson, R. Rapaport, and A. D. Rogol, "Consensus statement: management of the child born small for gestational age through to adulthood: a consensus statement of the International Societies of Pediatric Endocrinology and the Growth Hormone Research Society," Journal of Clinical Endocrinology and Metabolism, vol. 92, no. 3, pp. 804-810, 2007.

[5] M. M. Grumbach, B. S. Bin-Abbas, and S. L. Kaplan, "The growth hormone cascade: progress and long-term results of growth hormone treatment in growth hormone deficiency," Hormone Research, vol. 49, no. 2, pp. 41-57, 1998.

[6] R. Lanes, "Long-term outcome of growth hormone therapy in children and adolescents," Treatments in Endocrinology, vol. 3, no. 1, pp. 53-66, 2004.

[7] J. Bryant, L. Baxter, C. B. Cave, and R. Milne, "Recombinant growth hormone for idiopathic short stature in children and adolescents," Cochrane Database of Systematic Reviews, no. 3, Article ID CD004440, 2007.

[8] L. Baxter, J. Bryant, C. B. Cave, and R. Milne, "Recombinant growth hormone for children and adolescents with Turner syndrome," Cochrane Database of Systematic Reviews, no. 1, Article ID CD003887, 2007.

[9] P. Cohen, G. M. Bright, A. D. Rogol, A.-M. Kappelgaard, and R. G. Rosenfeld, "Effects of dose and gender on the growth and growth factor response to $\mathrm{GH}$ in $\mathrm{GH}$-deficient children: implications for efficacy and safety," Journal of Clinical Endocrinology and Metabolism, vol. 87, no. 1, pp. 9098, 2002.

[10] J.-C. Carel, E. Ecosse, M. Nicolino et al., "Adult height after long term treatment with recombinant growth hormone for idiopathic isolated growth hormone deficiency: observational follow up study of the French population based registry," British Medical Journal, vol. 325, no. 7355, pp. 70-73, 2002.

[11] B. Bakker, J. Frane, H. Anhalt, B. Lippe, and R. G. Rosenfeld, "Height velocity targets from the national cooperative growth study for first-year growth hormone responses in short children," Journal of Clinical Endocrinology and Metabolism, vol. 93, no. 2, pp. 352-357, 2008. 
[12] Novo Nordisk, Norditropin cartridges (somatropin [rDNA origin] injection) for subcutaneous use [prescribing information], Novo Nordisk, Princeton, NJ, USA, October 2008.

[13] Centers for Disease Control and Prevention, "Percentile data files with LMS values," http://www.cdc.gov/growthcharts/ percentile_data_files.htm.

[14] P. A. Lee and C. P. Houk, "Puberty and its disorders," in Pediatric Endocrinology, F. Lifshitz, Ed., pp. 273-303, Informa Healthcare, New York, NY, USA, 5th edition, 2007.

[15] S. R. Rose, D. I. Shulman, P. Larsson, L. R. Wakley, S. Wills, and B. Bakker, "Gender does not influence prepubertal growth velocity during standard growth hormone therapy-analysis of United States KIGS data," Journal of Pediatric Endocrinology and Metabolism, vol. 18, no. 11, pp. 1045-1051, 2005.

[16] D. Haffner, E. Wuhl, F. Schaefer, R. Nissel, B. Tonshoff, and O. Mehls, "Factors predictive of the short- and long-term efficacy of growth hormone treatment in prepubertal children with chronic renal failure. The German Study Group for Growth Hormone Treatment in Chronic Renal Failure," Journal of the American Society of Nephrology, vol. 9, no. 10, pp. 1899-1907, 1998.

[17] S. F. Kemp, J. Kuntze, K. M. Attie et al., "Efficacy and safety results of long-term growth hormone treatment of idiopathic short stature," Journal of Clinical Endocrinology and Metabolism, vol. 90, no. 9, pp. 5247-5253, 2005.

[18] P. Cohen, A. D. Rogol, C. L. Deal et al., "Consensus statement on the diagnosis and treatment of children with idiopathic short stature: a summary of the Growth Hormone Research Society, the Lawson Wilkins Pediatric Endocrine Society, and the European Society for Paediatric Endocrinology Workshop," Journal of Clinical Endocrinology and Metabolism, vol. 93, no. 11, pp. 4210-4217, 2008.

[19] P. A. Lee, S. D. Chernausek, A. C. S. Hokken-Koelega, and P. Czernichow, "International Small for Gestational Age Advisory Board consensus development conference statement: management of short children born small for gestational age, April 24-October 1, 2001," Pediatrics, vol. 111, no. 6, part 1, pp. 1253-1261, 2003.

[20] K. M. Attie, B.-A. Bengtsson, S. L. Blethen et al., "Consensus guidelines for the diagnosis and treatment of growth hormone (GH) deficiency in childhood and adolescence: summary statement of the GH research society," Journal of Clinical Endocrinology and Metabolism, vol. 85, no. 11, pp. 3990-3993, 2000.

[21] C. A. Bondy, "Clinical practice guideline: care of girls and women with Turner syndrome: a guideline of the Turner Syndrome Study Group," Journal of Clinical Endocrinology and Metabolism, vol. 92, no. 1, pp. 10-25, 2007.

[22] S. R. Kesler, "Turner syndrome," Child and Adolescent Psychiatric Clinics of North America, vol. 16, no. 3, pp. 709-722, 2007.

[23] M. L. Davenport, B. J. Crowe, S. H. Travers et al., "Growth hormone treatment of early growth failure in toddlers with Turner syndrome: a randomized, controlled, multicenter trial," Journal of Clinical Endocrinology and Metabolism, vol. 92, no. 9, pp. 3406-3416, 2007.

[24] T. Isojima, S. Yokoya, J. Ito, R. Horikawa, and T. Tanaka, "Trends in age and anthropometric data at start of growth hormone treatment for girls with Turner syndrome in Japan," Endocrine Journal, vol. 55, no. 6, pp. 1065-1070, 2008.

[25] I. P. Hughes, C. S. Choong, A. Cotterill, M. Harris, and P. S.W. Davies, "Gender bias in children receiving growth hormone treatment," Journal of Clinical Endocrinology and Metabolism, vol. 95, no. 3, pp. 1191-1198, 2010.
[26] A. Grimberg, E. Stewart, and M. P. Wajnrajch, "Gender of pediatric recombinant human growth hormone recipients in the United States and globally," Journal of Clinical Endocrinology and Metabolism, vol. 93, no. 6, pp. 2050-2056, 2008.

[27] B. S. Finkelstein, T. F. Imperiale, T. Speroff, U. Marrero, D. J. Radcliffe, and L. Cuttler, "Effect of growth hormone therapy on height in children with idiopathic short stature: a metaanalysis," Archives of Pediatrics and Adolescent Medicine, vol. 156, no. 3, pp. 230-240, 2002.

[28] L. Soriano-Guillen, J. Coste, E. Ecosse et al., "Adult height and pubertal growth in Turner syndrome after treatment with recombinant growth hormone," Journal of Clinical Endocrinology and Metabolism, vol. 90, no. 9, pp. 5197-5204, 2005.

[29] M. B. Ranke, A. Lindberg, P. Chatelain et al., "Derivation and validation of a mathematical model for predicting the response to exogenous recombinant human growth hormone $(\mathrm{GH})$ in prepubertal children with idiopathic $\mathrm{GH}$ deficiency. KIGS International Board. Kabi Pharmacia International Growth Study," Journal of Clinical Endocrinology and Metabolism, vol. 84, no. 4, pp. 1174-1183, 1999.

[30] M. B. Ranke and A. Lindberg, "Observed and predicted growth responses in prepubertal children with growth disorders: guidance of growth hormone treatment by empirical variables," Journal of Clinical Endocrinology and Metabolism, vol. 95, no. 3, pp. 1229-1237, 2010.

[31] A. A. Romano, K. Dana, B. Bakker et al., "Growth response, near-adult height, and patterns of growth and puberty in patients with Noonan syndrome treated with growth hormone," Journal of Clinical Endocrinology and Metabolism, vol. 94, no. 7, pp. 2338-2344, 2009.

[32] M. A. J. de Ridder, T. Stijnen, and A. C. S. HokkenKoelega, "Prediction of adult height in growth-hormonetreated children with growth hormone deficiency," Journal of Clinical Endocrinology and Metabolism, vol. 92, no. 3, pp. 925931, 2007.

[33] E. Cacciari, A. Cicognani, P. Pirazzoli et al., "Final height of patients treated for isolated GH deficiency: examination of 83 patients," European Journal of Endocrinology, vol. 137, no. 1, pp. 53-60, 1997. 